Canadian Journal of Family and Youth, 11(1), 2019, pp. 56-83

ISSN 1718-9748@ University of Alberta

http://ejournals,library,ualberta.ca/index/php/cjfy

\title{
Stumbling Along, Walking on Eggshells, and Vicious Circles: What Happens While Families Wait for Youth Substance Use Treatment
}

\author{
Laura Mills, Alexandre Dionne, Jennifer Bingley and Shelley L. Watson
}

\begin{abstract}
Youth substance use is a serious problem that has immediate and long-term impact on individuals, families, and society. Adolescent substance experimentation that develops into abuse foreshadows long-term problems, such as adult addiction, co-occurring mental illness, declined or abandoned academic careers, and other individual and interpersonal harms. Early and effective intervention can mitigate the harmful effects on the lives of young people, their families, and their communities. Intervention may not be accessible, however, for adolescents and/or their families when they seek help, and wait lists are common. Waiting for treatment for substance use is the focus of this study, and in particular, the experience of waiting and its associated impacts on the youth's substance use, involvement with police, running away, mental health and on the family unit. 118 parents of youth who use substances participated in a mixed methods study at Pine River Institute, a longterm residential youth treatment center. Clinical implications are discussed.
\end{abstract}

The authors would like to thank "Families for Addiction Recovery (www.farcanada.org) for funding this study. 
Mills, Dionne, Bingley and Watson

\section{Youth Addiction}

Youth substance use is a serious problem that has immediate and long-term implications for individuals, families, and society. Adolescent substance experimentation that develops into abuse foreshadows long-term problems, such as adult addiction (Dennis \& Scott, 2007), cooccurring mental illness (Hawkins, 2009), declined or abandoned academic careers (Canadian Centre on Substance Abuse, 2007), and other individual and interpersonal harms. Socially, early substance use has been linked to low graduation rates, lack of engagement in vocational pursuits, and considerable costs incurred for utilization of justice (Stenbacka \& Stattin, 2007) and hospital resources (Rhem et. al., 2006). Early and effective intervention can mitigate the deleterious impacts on the lives of young people, their families, and their communities. Interventive care, however, may not be accessible for adolescents and/or their families when they seek help. One of the reasons for this unmet need is treatment waiting lists.

Addiction is considered a mental illness, impacting the capacity to sustain daily functioning (National Institute of Drug Abuse, 2010), and youth aged 15-24 are more likely to report mental health challenges than people in any other age category (Nelson \& Park, 2006). There are several reasons mental health needs are not met, spanning stigma (Hansson, Jormfeldt, Svedberg, \& Svensson, 2011; Meredith et. al., 2009), particularly for clients who use drugs (Angermeyer \& Dietrich, 2006; Pesosolido, Monahan, Link, Stueve, \& Kikuzawa, 1999), client readiness, access issues, administrative hurdles, lack of available treatment, and waiting time for care (Breton, Plante, \& St-Georges, 2005; Corrigan, Kuwabara, \& O’Shaughnessy, 2009). Waiting for care is the focus of this study, with the goal of adding to existing knowledge about 
recommended wait times. In particular, we will explore the impact of waiting for treatment on the mental, behavioural, and relationship health of youth and their families.

\section{Waiting for Treatment}

Young people in Canada who need help for addictive behaviour are likely to wait for treatment, particularly if their need is deemed non-critical (Vallerand \& McLennan, 2012). Only $10 \%$ of agencies can meet the Canadian Psychiatric Association's one month wait time benchmark for scheduled care, $29 \%$ can meet the two-week benchmark for urgent care, and $46 \%$ can meet the 24-hour wait time recommended for imminent need (Canadian Psychiatric Association, 2015; Kowalewski, McLennan, \& McGrath, 2011). This approach to triage, while necessary for severe cases, is dangerous for those with moderate or mild clinical needs, who may worsen while waiting (Reid \& Brown, 2008).

Canada is not alone when it comes to waiting for health care. In 2001, the Institute of Medicine stated that the U.S. health system was overly concerned with urgent-care needs and recommended that patients receive care when and where needed (Institute of Medicine, 2001). Conversely, it has been suggested that wait times of less than one month for children with mental health problems may oversaturate the system, but wait times of over 30 weeks are too long (Foreman \& Hanna, 2000). Much of the information about ideal waiting time is based on waitlist attrition or first appointment attendance; more needs to be known about the experience of potential clients while waiting for care.

There is some information on health and behavioural consequences for those who wait for treatment. Many people will seek alternative help while maintaining their wait-list status at 
Mills, Dionne, Bingley and Watson

the initial agency. For example, among parents whose child (median age 11) required mental health services, $46 \%$ sought treatment while waiting (Schraeder \& Reid, 2015). Since so many clients-in-waiting seek other care, it would stand to reason that the mere prospect of future treatment is not meeting their needs. The consequences of waiting for treatment span substance use and mental health, and are summarized below.

\section{Substance Use Consequences}

Among treatment-seeking youth, those who wait deteriorate more so than their treated counterparts. For example, in one study, an eight-week motivational interviewing program reduced high school students' substance use more so than a group who waited eight weeks for the intervention. Among those on the waitlist, $27 \%$ reported daily use before waiting and $24 \%$ reported daily use after waiting. For those in the treatment group, $26 \%$ reported daily use before the intervention and $11 \%$ after. The waitlist group also reported significantly fewer reductions in substance related problems (e.g., attending work or school while high) than the group who received treatment (Stewart, Siebert, Arlt, Moise-Campbell, \& Lehinger, 2016). Additionally, in a meta-analysis that looked at substance use treatment studies, $66 \%$ of those who waited for treatment had worse substance use outcomes than those who received treatment (Davis et al., 2015). These findings suggest that treatment-seeking may be a catalyst for substance use change, but receiving treatment fosters better outcomes than waiting.

Mental health issues commonly co-occur with substance use problems. Compared to the general population in Canada, people with a mental illness are about twice as likely to have cooccurring substance use problems, and those who use substances are about three times more 
likely to have a mental health diagnosis than those without substance use problems (Centre for Addiction and Mental Health, 2017). A meta-analysis on the efficacy of brief, intensive and concentrated interventions for youth with anxiety problems demonstrated that treatment fostered better mental health than those in other conditions, particularly waitlists (Ost \& Ollendic, 2017). Another meta-analysis that reviewed the effectiveness of youth anxiety treatment revealed that treatment was more effective at reducing anxiety than waitlist, placebo, and treatment-as-usual groups (Erford, Kress, Giguere, Cieri, \& Erford, 2015). More extensive and broader information is needed about the waiting experience and consequences for youths who wait for treatment.

\section{Impact of Substance-Use on Families}

Previous research (Lander, Howsare, \& Byrne, 2013) has shown that, although each member of the family is affected by a family member's substance use differently, common problems include unmet developmental needs, impaired attachment, economic hardship, legal problems, and emotional distress. It is important to note that substance misuse has been termed the "family disease" by some researchers (Kumpfer, Alvarado, \& Whiteside, 2003), therefore, it is not surprising that family dynamics can also impact the substance-use of youth by negatively influencing the individual and unintentionally reinforcing the undesired behaviour (Santisteban et al., 2003). In other words, familial conflict and communication problems can contribute to the maintenance of deviant behaviours, and consequently uphold the substance-use problem (Santisteban et al., 2003).

\section{This Study}

Despite the deleterious impact that waiting for treatment has on youth, few studies have 
Mills, Dionne, Bingley and Watson

examined the family experience of waiting. Furthermore, to the authors' knowledge, no studies have been conducted that employ both quantitative and qualitative methods. To respond to this gap in information, using a mixed methods approach, we explored the mental, behavioural, and interpersonal impact on families and youth waiting for intensive residential substance use treatment.

\section{Methods}

Following Teddlie and Tashakkori's (2009) recommendations for mixed methods research, the researchers incorporated qualitative research informed by basic interpretive inquiry (Merriam, 2002, 2009). Participants responded to quantitative scales and open-ended questions. Examples of open-ended questions were, 'feel free to add any comments about your child's substance use' and, 'feel free to comment on your family's functioning'. Responses to openended questions were analyzed using a deductive approach to thematic analysis (Braun \& Clarke, 2006) to emphasize and deepen quantitative findings, plus explore the multiplicity of experiences in a family unit (Ambert, Adler, Adler, \& Detzner, 1995). After the themes were clearly defined, they were labeled using quotations taken directly from the interviews, which augmented theme validity (Guest, MacQueen, \& Namey 2012).

The mixed methods analysis presented here is a convergent parallel design, where the questionnaire and interview data were analyzed individually and then compared and contrasted with one another (Creswell, 2014).

\section{Participants}

As a part of the admission process at Pine River Institute (PRI), 118 consenting parents of 
substance abusing youth aged 13-19 participated in the study. PRI is a long-term residential youth treatment centre located in Ontario, Canada. It is a co-educational facility established in 2006, serving approximately 35 teenagers annually who struggle with addictive behaviour, as well as mental, behavioural, and relationship problems. Youth are most often referred by their parents and are typically poly-substance involved and use substances daily; have at least one mental health diagnosis; unsuccessful, stalled, or abandoned academic careers; experience with previous treatment, hospital visits and stays, criminality, running away; as well as chaotic family relationships and deviant peers.

PRI adopts a developmental approach to therapy, fostering maturity by strengthening empathy, interpersonal skills, moral values, emotion regulation, and future orientation. Youth first experience approximately two months of wilderness therapy after which they progress to a residential campus, and eventually a graduated transition to home, re-integrating with family and community. PRI families then work with an aftercare therapist to solidify and sustain their therapeutic gains. Family work is integral to the PRI approach and parents are expected to engage with the therapeutic process such that the youth's return home will foster lasting success.

\section{Procedure}

Initial applications to PRI, typically completed by a parent (most often mother), included demographic, academic, and health information, along with treatment, diagnosis, trauma, crisis, and criminal history and full disclosure option to consent to contribute to research and evaluation. Quantitative and qualitative measurement tools were embedded as part of the treatment engagement process. Families were placed on the waitlist in order of application and waited an average of 8.2 months $(S D=4.0)$ for entry. This waiting time is extensive for families 
Mills, Dionne, Bingley and Watson

in crisis. Reasons for this duration may be that PRI is one of few residential centers in the province and one of very few who offer treatment longer than a few months. Possibly, parents who feel that extended intensive care is the best approach for their child may be willing to wait, and often seek other therapy during the waiting period.

A few weeks before scheduled admission, families visited the PRI campus for a comprehensive assessment. Sixteen families chose to discontinue waiting. For both admitted and discontinued waiting families, another battery of qualitative and quantitative measures was administered as a post-wait measurement time-point. Indicators of youth health are more broad and deep than simply the reduction of substance use and so our measures in this study include relationships and behavior. All data in this study are parent-reported.

\section{Substance Use}

Two measures of substance use were used. The first, SU-4 is one question (developed inhouse) that asks parents to 'rate their child's substance use over the most recent three months', with four-response options: abstinent (1), social/occasional (2), periodic slips (3), or consistent and problematic (4). The second measure, SUBUSE, asks parents to 'indicate their child's substance use frequency during the most recent three months', with response options of never (0), yearly (1), monthly (2), weekly (3), and daily (4) for thirteen types of substances, most notably alcohol and marijuana.

\section{Family Functioning}

The McMaster Family Assessment Device (Epstein, Baldwin, \& Bishop, 1983) is a 
widely used 53-item self-report tool that assesses seven domains of family functioning, including general family functioning. Participants completed the General Family Functioning subscale (G-FAD), which has test-retest reliability estimate of .71 and high (i.e., $r>.5$ ) concurrent validity. Likert type response options range from strongly agree (4) to strongly disagree (1); 3 and higher indicates healthy family functioning.

\section{Running Away and Contact with Police}

We administered non-standardized questions asking whether youth had experienced running away or contact with police (yes/no) in the three months prior to survey completion.

The rationale for our use of non-standardized measures is two-fold. First, some questions were developed in-house collaboratively between the clinical and evaluation teams to resonate with the treatment language and as such, have face validity. Secondly, these measures were developed early in the life of the center and have the most data. Evaluation protocol is moving toward the use of standardized tools to measure all domains of health. All measures and procedures have been approved by York University's Research Ethics Board.

\section{Results}

Creswell and Tashakkori (2007) recommend that empirical mixed methods have two distinct "strands" of research findings (i.e., qualitative and quantitative), integrated to interpret the results. To that end, this results section presents mixed methods findings; participant responses on scale items are supplemented with qualitative themes. Results are structured by theme, which include a participant quote best deemed to represent the theme. All identifying 
Mills, Dionne, Bingley and Watson

information has been removed and youth names were replaced by ' $\mathrm{X}$ '. We examined changes

from pre- to post-wait for all rating scale variables using repeated measures ANOVA and for

dichotomous variables, McNemar's (1947) procedure was used to examine probability of change

during the waiting period.

We found that while adolescents were waiting for treatment, they continued to struggle

with substance use and mental health issues, running away and trouble with police. Each of these

challenges had a significant impact on their family. Specific areas of impact are discussed below,

but are collectively captured by one parent:

X's behaviours (\& health) has continued to deteriorate over the past 9 months while on the PRI wait list. We have struggled to maintain the sanctity of our home life - as X has become more dependent on substances (cigarettes, marijuana and alcohol); we have lost thousands of dollars to theft by X (jewelry, possessions, replaceable items) stolen \& sold to support his habits; the physical destruction of our home (broken doors, broken cabinets \& closets, cut wires). Finally, our very marriage is in jeopardy as we continue to struggle to advocate for $\mathrm{X}$ in our efforts to get him help.

\section{"He smokes weed several times a day": Substance Use}

Parents detailed their child's use of multiple substances, including alcohol, recreational drugs, as well as non-prescribed medication that continued despite their child being motivated for treatment. For example:

He has spent the last 3 years doing drugs (mostly marijuana) skipping school, stealing, getting into trouble, running away then getting sick of that and trying to turn it around by going to school, staying clean but then he goes back. And he starts the cycle again. It is a vicious circle. It does not end. Now he does marijuana every day. I am sure he has done other drugs as well. 
When looking at the open-ended pre-post responses, 50\% of participants reported either ongoing or increased substance use; quantitative findings for SU-4 conflicted, however, with the parents' open-ended responses, showing no difference on substance use from pre- to post-wait $\bar{x}_{\mathrm{pre}}=2.5(.53) \bar{x}_{\mathrm{post}}=2.48(.50) F_{(94)}=.29, p .=.59$ (n.s.), $\eta^{2}=.003$. On SUBUSE, alcohol use decreased during the waiting time $\bar{x}_{\text {pre }}=2.6$ (.79) $\bar{x}_{\text {post }}=1.6(1.0) F_{(48)}=50, p .<.001$ (n.s.), $\eta^{2}=.51$, but diminished substance use was not evident in reviewing open-ended questions. One mother noted, "increase in alcohol consumption, pot, suspect ecstasy, oxycotin...". Another stated, "Pot daily, cocaine? Other drugs? Alcohol anytime she can". One parent, who indicated increased alcohol consumption, speculated that her child was using alcohol as a substitute for other substances:

Following release from hospital, $\mathrm{X}$ began drinking alcohol, binge drinking by himself... most often to the point of vomiting (substituting one substance for another?) $\mathrm{X}$ has started cigarette smoking; was caught smoking marijuana under the deck.

The use of marijuana in particular was prevalent in most parent accounts, but quantitative SUBUSE analysis revealed that marijuana use decreased while families were waiting $\bar{x}_{\text {pre }}=3.7$ (.60) $\bar{x}_{\text {post }}=3.2(1.2) F_{(72)}=17.4, p .<.001$ (n.s.), $\eta^{2}=.20$. Open-ended responses indicated chronic marijuana use and many parents described increased marijuana use. One parent wrote, "Daily pot use. His life revolves round how/where/when he will get stoned". Youth's marijuana use appeared to increase when there was less daily structure, such as summer vacation or when not in school: "Constantly, daily, especially when she has no school".

Parents hypothesized why their children used substances, citing reasons of selfmedication for stress or mental health issues: 
Mills, Dionne, Bingley and Watson

$\mathrm{X}$ smokes marijuana (poppers) prior to going to school, sometimes at school, almost always between end of school and bedtime. X uses marijuana to shut down, to sleep.

It should be noted that parents expressed some difficulty in responding to specific questions, as they were not necessarily aware of their child's substance use details due to the youth being out of the family home or parents simply being unaware of the extent of the problem. One mother, for example, stated:

I believe $\mathrm{X}$ has tried numerous different drugs. Until this survey (which $\mathrm{X}$ filled out himself) I had no clue that his Current Drug of Choice was Oxy. So by filling out this form I learned something, my son's addiction is much greater than what I had initially thought.

\section{"It is breaking our family": Family Functioning}

As was demonstrated above, participants spoke of the prevalent use of substances impacting all family members. Family relationships were described as "uncomfortable, unhappy, stress, hurt, breakdown", “a cloud over all our heads", "family unit complete breakdown”, and "being worried sick almost every day". Parents expressed a lack of trust as "lies are daily", stealing of family members' possessions in search of money to purchase drugs, and a constant sense of unease in anticipation of the next challenge. One parent articulated,

Relationships have deteriorated. Trust is gone. We are walking on eggshells waiting for the next explosion. Hurt when he lies and steals and name calls. Scared when he disappears. Relief when we know where he is.

Quantitatively, there was no change on family functioning from pre- to post-wait $\bar{x}_{\text {pre }}=2.5(.53)$ $\bar{x}_{\text {post }}=2.48(.50) F_{(94)}=.29, p .=.59(n . s),. \eta^{2}=.003$. Open-ended responses, however, revealed 
ongoing family issues for most participants and in many cases, the child was no longer in the family home. The significant burden of the youth's substance use on family functioning, however, was prevalent throughout open-ended responses, and demonstrated profoundly by one mother:

His presence in a room brings in feelings of anxiety. We never know what will come out of his mouth (most times it is inappropriate). He will pick on a family member in order to purposely start a conflict. We walk on eggshells most of the time and are very careful what we do or say as to not start anything. Having to live like this has put a strain on a once happy healthy marriage. We are also worried about the effect this is having on our younger son. We are exhausted and try to do special things with him but often times we just can't do it. We tend to over react when the younger son does something minor. We don't have friends over much anymore because we never know if we are going to have to face the embarrassment of police at the door. We also don't stray too far from home because we are worried about what $\mathrm{X}$ is doing. We have also noticed that we are not invited to functions as often as we used to. We cannot plan holidays or activities because we never know what kind of state $X$ will be in. If he is in a good place he may go if not he will not go so planning things is very difficult and unfair to everyone else. Although we know that this is not productive, in order to keep peace in the household we oftentimes purposely separate ourselves from him, leaving him alone in the basement.

Parent responses indicated that family functioning was affected by both the substance use and waiting in general, plus thematic analysis revealed two subthemes: a change in the marital relationship and an impact on siblings and extended family members.

\section{“We are stumbling along": Impact on Marital and Social Relationships}

Many respondents specified deterioration of their marital or romantic relationships as a significant concern. Nine participants reported separation or divorce due to the strain on the family. Some spoke about how disagreements on how to handle their child led to marital discord; others mentioned constantly thinking about their child, which left little mental resources for their 
Mills, Dionne, Bingley and Watson

marital relationship. For example, one mother wrote, "Y and I agree for the most part about what to do about $\mathrm{X}$, but it is somewhat difficult on our relationship. I find myself obsessed with $\mathrm{X}$ and his issues. It occupies almost 24/7". Another participant stated, "my husband and I live in a constant state of worry, grief and anger" and another discussed how they "spend a great deal of time looking for answers and ways to mitigate his usage”.

\section{"Every relationship within this household is suffering for it": Impact on Siblings/Extended Family}

In addition to the effect on the marital relationship, respondents reported resentment, bitterness, and alienation among siblings. They also reported fear and distrust by extended family, leading to fewer family gatherings or the youth not being allowed to spend time with extended family. This damage was felt because of the drug-related behaviours such as stealing, and because the youth felt too shameful to face extended family members. As one parent described:

He can no longer babysit his younger nephews, has stolen from parents, and brother. Has lied to grandmother, parents, brother, and aunts and uncles. We have locks on our bedrooms to protect our belongings, he takes what he can get.

Parents characterized sibling relationships as "ruined" and one explained, "my other children are beginning to be very resentful of the situation and I am scared that it will break up their otherwise close bond with each other". The deleterious behaviours of youth also had implications beyond the family unit when they included illegal activities.

\section{“Breaking probation, smoking, doing drugs, running away, threatening staff and others": Contact with Police}

Youth waiting for treatment engaged in a variety of illegal behaviours, which often 
translated into contact with law enforcement (e.g., three youth were incarcerated or in a diversion program; eight had charges related to substance use, such as possession or intoxication). Parents described multiple incidents of violence (e.g., bullying, assault charges, rage) and some recounted being kicked, spat at, or threatened. Many parents also referred to their child stealing money or items from family members and neighbours.

Illegal behaviours and continued substance use described in open-ended questions demonstrate continued or escalating externalizing behaviours, suggesting that the adolescent is not coping. One parent noted, "currently incarcerated. Even the arresting police officer said the following to our lawyer: This kid doesn't belong here, you need to help him”. The illegal behaviours were another way of indicating struggles as youth wait for treatment.

Quantitative analyses indicate that before PRI, $42 \%$ of parents report youth police contact in the three months before parents completed the survey, about half of whom again had police contact while waiting. Of the $58 \%$ whose child had no police contact before waiting, about onethird had contact with police during the waiting period (Table 1). These proportions indicated no significant tendencies in terms of probability of increasing or decreasing contact with police (McNemar's; $N=108, p=.45)$.

\section{"He frequently will not come home at night": Running Away}

Almost all respondents mentioned their child being away from home, but most articulated that it wasn't so much "running away", but "missing" or "not coming home". One mother explained, "Missing is perhaps the better word. She was placed on a missing persons list and detectives were looking for her... 3 days." Some families reported their youth living in a shelter; other youths were living with extended family members. Leaving the family home was often 
Mills, Dionne, Bingley and Watson

noted as happening after a fight with parents or "having to take responsibility for their actions".

Many parents described a cycle of the child being in and out of the house, as demonstrated by this mother's response: "usually X just leaves because she won't comply with the rules of the house. She is gone a day or two and then texts us or shows up". Another parent wrote:

We say if you bring illegal substance into our home you can't live here. He hears get out. He has left twice and once camped in a field and the second time broke into a seasonally used home. He has a cell phone and we have called and brought him home both times in under 24 hours. The third time we called the police because it was -12 and he didn't have anywhere to go. They took him to a youth shelter and he is there presently. 2013- We have tried to integrate X back into our home from September to January and we have been unsuccessful.

As this quote demonstrates, a child "missing" from the family occurred for a variety of reasons, but mostly a failure to abide by the family rules, whether the child was trying to hide their drug use or the parent asked the child to leave. As one participant described, "X doesn't want us to know that she is drinking and taking drugs. So, she goes out to do it and doesn't come home until she is sober. Sometimes 4 days later." Another stated, "she doesn't run away, she just goes out and doesn't come back till she's ready (or sober) or doesn't have anywhere else she can go".

Despite many participants describing the "missing" behaviour of the child in the openended section of the questionnaire, quantitative analyses show a significant tendency was found for youth to decrease their "running away" behaviour more so than increase their running behaviour $(p<.001)$. As seen in Table 3, about two-thirds of parents reported youth running away before waiting, about a quarter of whom ran away during the wait. Among the third whose youth did not run away before waiting, one in seven ran away while waiting. 
Despite the incongruence between the quantitative and qualitative results, open-ended responses revealed running away to be a considerable area of concern for families, especially when waiting for treatment. It should also be noted that post-wait, many of the children were no longer living in the family home, and rather were either living in shelters, "couch surfing", or living with other family members. One parent expressed increased unplanned time away from home as a direct reaction to waiting for treatment:

He will occasionally stay out all night, frequently sleep over at the houses of friends. He usually can't be bothered to let us know what his plans are. He still calls in order to get rides home. He generally prefers to sleep in his own bed at home. That has changed in the very recent past, as $\mathrm{X}$ has gotten frustrated with us and with the length of time it's taken to get him treatment. He has said today that he will move out until we find him a treatment centre.

\section{"Mental health? Addiction? Chicken? Egg? Does it matter which came first?? HE IS SUFFERING": Mental Health}

Mental health was a thread that was woven through the responses for all questions, whether they were about substance use, family, running away, or police contact. Parents reported their children displaying volatile behaviours such as hostility, violence, or aggression.

Additionally, some parents described more internalized problems such as depression, anxiety, bipolar disorder, self-harm (e.g. 'cutting herself so many times'), and low self-regulation such as mood swings, intrusive thoughts, throwing up every day before school, and panic attacks. The complexity of problems for these youth was expressed as multi-faceted, for example, one parent noted, "He is scheduled to start this program in September, but we have no confidence he will be able to succeed without treatment of his ADHD, substance use, and mental health issues".

Some parents indicated that youth refuse to take prescribed psychotropic medication, whereas many parents discussed how the youth preferred to "self-medicate" with marijuana or 
Mills, Dionne, Bingley and Watson

other substances. To demonstrate, one parent wrote, " $\mathrm{X}$ knows he is bipolar and that it needs to be addressed but can't be bothered taking his meds. He thinks the pot helps".

When addressing the differences pre- and post-waiting, it is the mental health needs that are most striking. Only 2 participants reported improved mental health; many parents described ongoing or worsening symptoms, such as increased suicidal ideation and depression. The need for immediate supports is evident in the parents' reports that they are desperate but lack the resources to help quell their youth's escalating internalizing and externalizing behaviours. As one parent articulated:

$\mathrm{X}$ has a glow inside him. It has significantly been dimmed this past year $+\ldots$ and especially this past 2 months have been HORRIFIC. HE needs to find himself again. He WANTS the help. HE knows his behavior, actions and vile outbursts are unacceptable (he said disgusting things to me on December 3rd in front of my 79 year old father). But he knows it's wrong - he can't control it - and it makes him hate himself even more. He loves his parents. He knows that we love him. But he is also smart enough to know how much turmoil and extreme sadness he has caused our family. Vicious cycle. I LOVE MY SON. I want him TO LOVE HIMSELF. i want him to recognize ALL of his gifts. I want him desperately to be happy and have a SAFE and fulfilling future that he can be proud of.

These issues point to the need for substance use treatment and further, demonstrate the risks associated with an individual having to wait for treatment.

\section{Discussion}

In Canada, an estimated $\$ 50$ billion per year is spent on mental health care, social services, and lost productivity. About 20\% of Canadians aged 4-17 have mental health problems, $0.8 \%$ of those aged 9-17 experience substance use problems (Waddell, McEwan, Shepherd, Offord, \& Hua, 2005) and in 2011, it was found that 7\% of Canadians aged 9-19 had substance use disorder (Mental Health Commission of Canada, 2013). A concerning finding is that less 
than half who experience problems seek help (Lisage et. al., 2006), and less than one quarter who need help receive specialized services (Waddell et. al., 2005). Waiting for treatment has been noted as one of the reasons for lack of access to service; when youth wait for mental health treatment, they are likely to disengage with the process and the longer the wait, the less likely the treatment engagement (Folkins, Hersch, \& Dahlen, 1980; Westin, Barksdale, \& Stephan, 2014).

Previous quantitative studies have indicated that substance abusing youth who are placed on waitlists fare worse than treated youth. To the authors' knowledge, however, there is little information about the experiences of the waiting youth and families. This study explored these experiences among a group of families who applied and waited for intensive youth addiction treatment at Pine River Institute. We established three notable findings: the breadth of problems extends beyond simple substance misuse; waiting youth experienced increased internalizing and externalizing problems; and qualitative findings gave context and nuance to, and sometimes conflicted with, quantitative analyses.

The problems across family relationships, contact with the law, running away, and mental health shed light on the complexity involved with substance abusing youth. In all domains, parent open-ended responses indicated problems that were ongoing or had worsened while waiting and may be particularly problematic when youth are not occupied in daily schedules such as school. The general sense was that parents were surviving in a state of tumultuous chaos, expending all resources just to survive as a family until admission to PRI. Participants also spoke to family breakdown and a significant impact on the family. The scope of the impact on families was systemic, involving parents, siblings, and extended family members. Parent observations of youth reveal that their mental health and capacity for resilience to everyday stressors was highly 
Mills, Dionne, Bingley and Watson

compromised and a continued struggle through the waiting process.

We found that quantitative investigation alone was not enough to capture the depth or breadth of what these parents experience while waiting for treatment. Indeed, in some cases, our quantitative findings indicated that some youth improved while waiting, but this was clearly not the case according to parent reports, which revealed a decline in youth and family health during the waiting period. There are a few possible reasons for this disparity. First, when parents apply, they may respond to quantitative surveys as though their current situation is the worst they have experienced, thus at the lowest end of the scale; then during the waiting period, problems worsen, which emerges in the open-ended responses. Second, no measurement tool could capture the myriad nuances of youth and family health and as such, changes in health could not possibly all be captured by any quantitative measure. However, participants were able to express their concerns in the open-ended section of the questionnaire. The advantage of mixed methods is that using both qualitative and quantitative approaches allow for a greater degree of trustworthiness and facilitates a superior depth of topic examination (Creswell, 2014; Guest et al., 2012; Teddlie \& Tashakkori, 2009).

\section{Limitations}

While the open-ended questions provided rich data and contextualized the close-ended responses, we did not follow up with respondents to obtain more detailed responses. Some parents provided more comprehensive responses while others did not offer many details in the open-ended sections of the questionnaire. Future research should include interviews or focus groups, which would allow the researchers to further understand the complexity of the issues, as well as the contextualized impact pre-and post-waiting for treatment. In particular, it would have 
been beneficial to follow up about mental health concerns and other addictive behaviours, as well as the link between contact with police and running away behaviour. The open-ended questions also failed to evaluate specific waitlist times for families, therefore we could not explore the impact of varied wait times.

Parents were asked to reflect on youth health, behaviour, and relationships in the context of the waiting period. It is possible, however, that timelines may be blurred by day-to-day living and particularly, in the midst of family crisis, hard to recall exact timepoints. As such, some of the reflective responses might span beyond the waiting time anchor and instead more generally reflect the experience of life with a substance-abusing youth.

Another limitation is the possibility that parents under- or over-report problem severity with the intention of qualifying for and expediting admission to their treatment of choice. For some of our quantitative measures (e.g., substance use), we adopted more than one tool and ran informal checks that indicate good reliability between tools. This is not a certain method of avoiding the social desirability bias but does give us some confidence that our parent reports are accurate.

\section{Future Research}

Mental health issues are only briefly discussed in this paper. Throughout the open-ended questions, parents referred to specific mental health diagnoses such as anxiety, ADHD, and depression, but also described other addictive behaviours such as gaming and social media. More in-depth work on mental health changes while waiting is warranted, as is the link between other mental health issues and substance use. 
Mills, Dionne, Bingley and Watson

\section{Conclusion}

This paper was an exploration of the effects of waiting for treatment on families and youth who experience youth substance use. These effects were deleterious, in some cases leaving youths and their families vulnerable to significant harms, and communities subject to increased costs through taxation on justice and health care systems. These preliminary findings highlight the need for youth to have timely access to effective treatment. In particular, youth and their families who seek intensive treatment are often the most vulnerable - mired in an array of interwoven and complex problems that worsen when waiting periods defer necessary treatment. With nearly two-thirds of Pine River Institute applicants having experienced previous treatment, it's clear that continued treatment-seeking behaviour is an appeal for effective help for these vulnerable youth. Waiting for effective treatment is simply not ideal. 


\section{References}

Ambert, A-M., Adler, P., Adler, P., \& Detzner, D. F. (1995). Understanding and evaluating qualitative research. Journal of Marriage and the Family, 57, 879-893.

Angermeyer, M. C., \& Dietrich, S. (2006). Public beliefs about attitudes toward people with mental illness: A review of population studies. Acta Psychiatrica Scandinavica, 113, 163179.

Braun, V. \& Clarke, V. (2006). Using thematic analysis in psychology. Qualitative Research in Psychology, 3 (2), 77-101.

Breton, J-J., Plante, M. A., \& St-Georges, M. (2005). Challenges facing child psychiatry in Quebec at the dawn of the $21^{\text {st }}$ century. Canadian Journal of Psychiatry, 50, 203-212.

Canadian Centre on Substance Abuse. (2007). Substance Abuse in Canada: Youth in Focus. Ottawa, ON: Canadian Centre on Substance Abuse.

Canadian Psychiatric Association. (2015). Wait time benchmarks for patients with serious psychiatric illnesses. Wait Time Alliance. Available from: https://www.cpa-apc.org/wpcontent/uploads/Wait_times-CPA_policy_paper_1-web-EN.pdf

Centre for Addiction and Mental Health. (2017). Mental Illness and Addictions: Facts and Statistics. Toronto, ON. CAMH. Retrieved from http://www.camh.ca/en/hospital/about_camh/newsroom/for_reporters/Pages/addictionme ntalhealthstatistics.aspx.

Corrigan, P. W., Kuwabara, S. A., \& O’Shaughnessy, J. (2009). The public stigma of mental illness and drug addiction: Findings from a stratified random sample. Journal of Social Work, 9, 139-147.

Creswell, J. (2014). Research design (4th ed.). Thousand Oaks, CA: Sage Publications Inc.

Creswell, J. W. \& Tashakkori, A. (2007). Developing publishable mixed methods manuscripts. Journal of Mixed Methods Research, 1, 107-111.

Davis, M. L., Powers, M. B., Handelsman, P., Medina, J. L., Zvolensky, M., \& Smits, J. A. J. (2015). Behavioural therapies for treatment-seeking cannabis users: A meta-analysis of randomized controlled trials. Evaluation \& the Health Professions, 38, 94-114.

Dennis, M. \& Scott, C. (2007). Managing addiction as a chronic condition. Addiction Science \& Clinical Practice, 4, 45-55.

Epstein, N. B., Baldwin, L. M.,. \& Bishop, D. S. (1983). The McMaster Family Assessment Device. Journal of Marital and Family Therapy, 9, 171-180. 
Mills, Dionne, Bingley and Watson

Erford, B. T., Kress, V. E., Giguere, M., Cieri, D., \& Erford, B. M. (2015). Meta-analysis: Counseling outcomes for youth with anxiety disorders. Journal of Mental Health Counseling, 37, 63-94.

Foreman, D. M. \& Hanna, M. (2000). How long can a waiting list be? The impact of waiting time on intention to attend child and adolescent psychiatric clinics. Psychiatric Bulletin, 24, 211-213.

Folkins, C., Hersch, P., \& Dahlen, D. (1980). Waiting time and no-show rate in a community mental health center. American Journal of Community Psychology, 8, 121-123.

Guest, G., MacQueen, K., \& Namey, E. (2012). Applied thematic analysis. Thousand Oaks, CA: Sage Publications Inc.

Hawkins, E. H. (2009). A tale of two systems: Co-occurring mental health and substance abuse disorders treatment for adolescents. Annual Review of Psychology, 60, 197-227.

Hansson, L., Jormfeldt, H., Svedberg, P., \& Svensson, B. (2011). Mental health professionals' attitudes towards people with mental illness: Do they differ from attitudes held by people with mental illness? International Journal of Social Psychiatry, 59, 48-54.

Institute of Medicine (2001). Crossing the quality chasm: A new health system for the $21^{\text {st }}$ century. Washington, DC. National Academies Press.

Kowalewski, K., McLennan, J. D., \& McGrath, P. J. (2011). A preliminary investigation of wait times for child and adolescent mental health services in Canada. Journal of Canadian Child \& Adolescent Psychiatry, 20, 112-119.

Kumpfer, K.L., Alvarado, R., \& Whiteside, H.O. (2003). Family-based interventions for substance use and misuse prevention. Substance Use \& Misuse, 38, 11-13.

Lander, L., Howsare, J., \& Byrne, M. (2013). The impact of substance use disorders on families and children: From theory to practice. Social Work in Public Health, 28, 194-205.

Lisage, A., Vasiliadis, H. M., Gange, M. A., Dudgeon, S., Kasman, N., Hay, C. (2006, January) Prevalence of mental illnesses and related service utilization in Canada: An analysis of the Canadian Community Health Survey. Mississauga, ON: Canadian Collaborative Mental Health Initiative. Available at: www.ccmhi.ca.

McNemar, Q. (1947). Note on the sampling error of the difference between correlated proportions or percentages. Psychometrika, 12, 153-157. 
Mental Health Commission of Canada (2013, January 15). Making the Case for Investing in Mental Health in Canada. Retrieved from https://www.mentalhealthcommission.ca/sites/default/files/201606/Investing_in_Mental_Health_FINAL_Version_ENG.pdf.

Meredith, L. S., Stein, B. D., Paddock, S. M., Jaycox, L. H., Quinn, V. P., Chandra, A., \& Burnam, A. (2009). Perceived barriers to treatment for adolescent depression. Medical Care, 47, 677-685.

National Institute of Drug Abuse. (2010, September). Is drug addiction a mental illness? Retrieved from: https://www.drugabuse.gov/publications/research-reports/comorbidityaddiction-other-mental-illnesses/drug-addiction-mental-illness.

Nelson, C. H. \& Park, J. (2006). The nature and correlates of unmet health care needs in Ontario, Canada. Social Science \& Medicine, 62, 2291-2300.

Ost, L-G. \& Ollendic, T. H. (2017). Brief, intensive and concentrated cognitive behavioural treatments for anxiety disorders in children: A systematic review and meta-analysis. Behaviour Research \& Therapy, 97, 134-145.

Pesosolido, B. A., Monahan, J., Link, B. G., Stueve, A., \& Kikuzawa, S. (1999). The public's view of the competence, dangerousness, and need for legal coercion of persons with mental health problems. American Journal of Public Health, 89, 1339-1345.

Reid, G. J. \& Brown, J. B. (2008). Money, case complexity, and wait lists: Perspectives on problems and solutions at children's mental health centers in Ontario. The Journal of Behavioural Health Sciences \& Research, 35, 334-346.

Rhem, J., Baliunas, D., Brochu, S., Fischer, B., Gnam, W., Patra, J., Popoa, S., Sarnocinska-Hart, A., \& Taylor, B. (2006). The costs of substance abuse in Canada: Highlights. Ottawa: Canadian Centre of Substance Abuse.

Santisteban, D.A., Coatsworth, J.D., Perez-Vidal, A., Kurtines, W.M., Schwartz, S.J., LaPierrere, A., \& Szapocznik, J. (2003). Efficacy of brief strategic family therapy in modifying Hispanic adolescent behavior problems and substance use. Journal of Family Psychology, 17, 121-133.

Schraeder, K. E. \& Reid, G. J. (2015). Why wait? The effect of wait-times on subsequent helpseeking among families looking for children's mental health services. Journal of Abnormal Child Psychology, 43, 553-565.

Stenbacka, M. \& Stattin, H. (2007). Adolescent use of illicit drugs and adult offending: a Swedish longitudinal study. Drug \& Alcohol Review, 26, 397-403. 
Mills, Dionne, Bingley and Watson

Stewart, D. G., Siebert, E. C., Arlt, V. K., Moise-Campbell, C., \& Lehinger, E. (2016). READY or Not: Findings from a school-based MI intervention for adolescent substance use. Journal of Substance Abuse Treatment, 71, 23-29.

Teddlie, C. \& Tashakkori, A. (2009). Foundations of mixed methods research: Integrating quantitative and qualitative approaches in the social and behavioral sciences. London: Sage.

Vallerand, I. A. \& McLennan, J. D. (2012). Child and adolescent mental health service management strategies that may influence wait times. Journal of Canadian Child and Adolescent Psychiatry, 22, 159-165.

Waddell, C., McEwan, K., Shepherd, C. A., Offord, D. R., \& Hua, J. M. (2005). A public health strategy to improve the mental health of Canadian children. Canadian Journal of Psychiatry, 50, 226-233.

Westin, A. M. L., Barksdale, C. L., \& Stephan, S. H. (2014). The effect of waiting time on youth engagement to evidence based treatments. Community Mental Health Journal, 50, 221 228. 


\section{Table 1}

Information on Admitted Youths to Pine River Institute

\begin{tabular}{lcc} 
& $N$ & Mean $(S D)$ \\
\hline Age at Application & 113 & $16.0(1.5)$ \\
Number of Siblings & 102 & $1.5(1)$ \\
Missed work (PP) & 83 & $9(14.8)$ \\
Missed work (SP) & 72 & $5.2(8)$ \\
Highest grade completed & 102 & $9.4(1.3)$ \\
Current grade & 110 & $10.5(1.1)$ \\
\hline
\end{tabular}

Proportion

\begin{tabular}{lcc}
\hline Male & 117 & $64 \%$ \\
Parents Together & 93 & $63 \%$ \\
Behind on school credits & 95 & $79 \%$ \\
Previous treatment & 118 & $64 \%$ \\
Independent Education Plan & 77 & $53 \%$ \\
Anxiety Diagnosis & 56 & $48 \%$ \\
Depression Diagnosis & 72 & $67 \%$ \\
Bipolar Diagnosis & 47 & $13 \%$ \\
Eating Disorder & 44 & $11 \%$ \\
OCD Diagnosis & 49 & $12 \%$ \\
Panic Disorder Diagnosis & 45 & $7 \%$ \\
PTSD Diagnosis & 45 & $7 \%$ \\
Schizophrenia Diagnosis & 42 & $5 \%$ \\
Social Phobia Diagnosis & 47 & $19 \%$ \\
AOD Abuse Diagnosis & 58 & $53 \%$ \\
AOD Dependence Diagnosis & 47 & $28 \%$ \\
ADHD Diagnosis & 64 & $56 \%$ \\
Other Mental Health Diagnosis & 25 & $32 \%$ \\
& & \\
\hline
\end{tabular}


Mills, Dionne, Bingley and Watson

Table 2

Parent Reported Youth Police Contact in Most Recent Three Months

\begin{tabular}{lr|cc}
\hline \multirow{2}{*}{ Recent Police Contact (N=108) } & \multicolumn{2}{|c}{ Post-Wait } \\
& No & Yes \\
\hline \multirow{2}{*}{ Pre-Wait } & No & $23 \%$ & $18 \%$ \\
& & & \\
\hline
\end{tabular}

Table 3

Parent Reported Youth Running Away in Most Recent Three Months

\begin{tabular}{lr|cc}
\hline \multirow{2}{*}{ Recent Running Away (N=108) } & \multicolumn{2}{|c}{ Post-Wait } \\
& No & Yes \\
\hline \multirow{2}{*}{ Pre-Wait } & Yes & $49 \%$ & $16 \%$ \\
& & & \\
\hline
\end{tabular}

